\title{
ANNOUNCEMENT
}

(c) The Japan Wood Research Society 2017

Mokuzai Gakkaishi (Journal of the Japan Wood Research Society)

Mokuzai Gakkaishi is another official journal of the Japan Wood Research Society. This journal publishes original articles, notes, review articles, and announcements from the Society in Japanese but with English abstracts, tables, and figure captions for original reports. Contents of the latest issue of Mokuzai Gakkaishi are as follows:

Volume 63 Number 32017

\section{Category I}

Ayaka Murai, Takashi Tanaka, Masaaki Yamada Nondestructive evaluation of water-based polymer-isocyanate adhesive distribution in glued laminated timber using X-rays

\section{Category II}

Kuniyoshi Shimizu, Yuri Yoshimura, Toshinori Nakagawa, Sayaka Matsumoto, Yuki Washioka, Eriko Haga, Akiyoshi Honden, Taisuke Nakashima, Hiromi Saijo, Koki Fujita, Yuichiro Watanabe, Genichi Okamoto, Shinshi Inoue, Shinji Yasunari, Juu Nagano, Yuki Yamada, Tsuyoshi Okamoto, Koichiro Onuki, Hiroya Ishikawa, Noboru Fujimoto

Analysis of volatile compounds and their seasonal changes in rooms using sugi (Cryptomeria japonica) wood boards as interior materials

\section{Category III}

Hirokazu Ito, Shinji Ogoe, Masaki Okamoto, Shigehiko Suzuki, Yoichi Kojima, Hikaru Kobori, Akiko Isa, Takashi Endo

Properties of fibrillated wood flour, and of wood-plastic composites made with fibrillated wood flour 